\title{
Correlation of Serum Neopterin level with Complement C3, C4 in assessment of Systemic Lupus Erythematosus Activity Farag Khalil ${ }^{\mathrm{a}}$, Abd Elwahab M. Lotfy ${ }^{\mathrm{a}}$, Ahmed A. Abd Elshafy ${ }^{\mathrm{a}}$, Mohammad A. Khedr ${ }^{\mathrm{b}}$ ${ }^{a}$ Internal Medicine Department Faculty of Medicine Al Azhar University, Cairo, Egypt. \\ ${ }^{b}$ Clinical Pathology Department Faculty of Medicine Al-Azhar University, Cairo, Egypt. Correspondence to: Farag Khalil, Lecturer of internal medicine, Faculty of Medicine Al-Azhar University, Alhusein University Hospital, Internal Medicine Department Cairo, Egypt. \\ Email: dr.farag7070@azhar.edu.eg
}

\begin{abstract}
:
Background: Systemic lupus erythematosus (SLE) has a recurrent disease activity throughout the natural course of the disease. Assessment of this activity is often complex and time consuming. To date no measures have been created specifically for SLE. Studying serum neopterin and comparing it with other established parameters C3, C4 may add benefit for SLE follow up. Aim: The aim of our study is to evaluate the level of serum neopterin in patient with systemic lupus erythematosus (SLE) as a marker of disease activity and its correlation with other parameters of disease activity. Patients and methods: Seventy five subjects; 60 patients with (SLE); 30 of them are active and another 30 with no activity and 15 healthy subjects as a control group. Results: Serum neopterin was higher in the active group than the inactive group and a significant difference between the patients with SLE group than controls group was also reported. Our results shows that the mean value of serum neopterin in whole SLE patients $(21.9 \mathrm{ng} / \mathrm{ml})$ and the serum neopterin in the active and inactive groups was $33.9 \mathrm{ng} / \mathrm{ml}$ and $3.45 \mathrm{ng} / \mathrm{ml}$ respectively which were highly significant than the mean value of the control group $(\mathrm{P}<0.001)$. Also the differences between the three groups was highly significant $(\mathrm{P}<0.001)$. Conclusion: As increased serum neopterin levels were found in patients with SLE and were correlated with certain clinical and laboratory immunoinflammatory parameters then estimation of serum neopterin levels seems beneficial in the assessment of disease activity and evaluation of the efficacy of various treatment regimens used.
\end{abstract}

Key words: SLE, Serum Neopterin, Lupus nephritis

\section{Introduction}

Systemic lupus erythematosus (SLE) is a multisystem autoimmune disease characterized by chronic inflammation and the production of autoantibodies directed against numerous antigen which target multiple organ systems including joints, skin and kidneys. The relapsing-remitting pattern of disease, along with the clinical heterogeneity makes SLE not only one of the challenging autoimmune disorders to diagnose but also to treat and assess drug efficacy ${ }^{(\mathbf{1})}$.

Human monocyte- derived macrophages upon stimulation with the cytokine interferon gamma (INF- $\gamma$ ) released from activated Tlymphocytes produce a substances called neopterin (6-D-erytro-trihydroxypropylpterin) formed from intracellular guanosine triphosphate. Also other interferons, interleukin- $1 \alpha$ (IL- $1 \alpha)$, tumor necrosis factor- $\alpha$ (TNF- $\alpha$ ) and lipopolysaccharides affect neopterin production ${ }^{(2)}$.

The concentration of neopterin have been increased in vivo in patients with diseases associated with the activation of cell-mediated immunity (e.g., during allograft rejection, acute viral infection, intracellular bacteria, parasites, autoimmune disease and malignant tumor cells). The neopterin level provides appropriate information regarding the extent and activity of the pathological process ${ }^{(3)}$.

The complement has been recognized one as pivotal part of innate and adaptive immune system and it had three well-known physiological activities including host defense against infection, bridging interface between innate and adaptive immunity, and disposal of waste immune complex or apoptotic cells ${ }^{(4)}$.

The significantly increase of serum neopterin level in SLE while the complement C3, C4 levels was significantly lower than those of healthy controls make neopterin as one of the parameters that showed significantly higher levels in SLE with mild activity ${ }^{(5)}$.

\section{Subject and Methods}

Type of the study: a cross-sectional observational study.

Site and time of the study: Internal Medicine Department, Faculty of Medicine, Al-Azhar 
University Cairo and Tanta Dialysis Unit. Subjects: This study was carried out on sixty female patients suffering from systemic lupus erythematosus (SLE) attending the outpatient and inpatient clinics in Internal Medicine Department as well as inpatients at Tanta and Al-Azhar University Hospitals. The study included also 15 apparently healthy female individual of matched age as a control group. All patients were females and their ages ranged from (18-40) years and the disease duration ranged from (6 months -5 years).

Diagnosis of SLE was based on the revised criteria of the American College of Rheumatology for the classification of SLE, which were modified by Hochberg ${ }^{(6)}$.

The activity of the disease was measured by Systemic Lupus Disease Activity Index (SLEDAI).

\section{Subjects in the study have been classified in three groups:}

GroupI: 30 patients with active systemic lupus erythematosus (SLEDAI > 6).

Group II: 30 patients with inactive systemic lupus erythematosus $(\mathrm{SLEDAI} \leq 6)$.

Group III: 15 healthy female individual of matched age and sex as a control group apparently free from any relevant disease, their ages ranged from (19-39) years.

\section{Ethical considerations:}

a) Before data collection, verbal consent was granted from the ethical committee of AlAzhar Faculty of Medicine.

b) Informed consent was obtained from every patient to participate in this study.

c) Proper treatment for diseased cases was prescribed.

\section{Methods:}

All subjects were subjected to

A- Detailed history taking.

B- Full clinical examination.

C- Routine laboratory investigations: Erythrocyte sedimentation rate (ESR), Creactive protein (CRP), fasting and 2 hours postprandial blood glucose, complete blood count (CBC), complete urine analysis, and liver and kidney function test.

D- Measurement of proteins in 24 hour urine (g/24 hrs).

E- (ANA) Anti-nuclear Abs. and Anti-ds. DNA assay by IF (immuno-fluorescence) technique. Titer of $1 / 40$ or more is considered positive. (Done for SLE patients only).
F- Serum complement levels $(\mathbf{C 3}, \mathbf{C 4})$ : Done by nephelometry (Normal level of $\mathrm{C} 3$ is 84$160 \mathrm{mg} / \mathrm{dl}$ and for $\mathrm{C} 4$ is $12-36 \mathrm{mg} / \mathrm{dl}$ ). (Done for SLE patients only).

\section{G- Specific laboratory investigation:}

- Serum neopterin level by ELISA assay.

\section{- Statistical analysis:}

- Statistical Package for Social Science (SPSS) version 17 was used. Quantitative data were expressed as mean \pm SD and qualitative data were expressed as number and percentage of the total. The mean and standard deviation (SD) were calculated. Comparing the mean \pm SD of 3 groups was done using the one-way ANOVA test ( $\mathrm{F}$ test). Scheffe test was used as a post-hoc test. Spearman's test was used for the correlation analysis. Fisher's exact test used for comparative study of Anti- ds- DNA. Determining the extent that a single observed series of proportions differs from a theoretical or expected distribution was done using the Yate's corrected Chi square test. $\mathrm{P}$ was considered non-significant if $>0.05$, significant if $<0.05$ and highly significant if $<0.01$ and $<0.001$.

\section{Results \\ Our study showed that:}

- The mean value of serum neopterin in whole SLE patients $(21.9 \mathrm{ng} / \mathrm{ml})$ ranged between (1.7-82.5).

- The mean values of serum neopterin for the active and inactive groups was 33.9 $\mathrm{ng} / \mathrm{ml}$ and $3.45 \mathrm{ng} / \mathrm{ml}$ respectively where they were highly significant than the mean value of the control group (1.95 $\mathrm{ng} / \mathrm{ml})(\mathrm{P}<0.001)$.

- Also the differences between the three groups were highly significant $(\mathrm{P}<0.001)$.

From above, we conclude that for our marker serum neopterin, there was highly significant increase of its values for the patients with active SLE as compared with the healthy control group with P-value of $0.001 * *$. In a same manner, $S$. Neopterin for inactive SLE group compared with healthy control group showed highly significant correlation with p. value of $0.001 * *$ (Table 1 ). 
Table (1): Serum neopterin level among SLE patients and control group.

\begin{tabular}{||l|l|l|l|}
\hline Serum neopterin & Active SLE & Inactive SLE & Control \\
\hline Mean & 33.9 & 3.45 & 1.95 \\
\hline \pm SD & 8.36 & 0.81 & 0.67 \\
\hline p. value & 0.001 & \\
\hline Scheffe test & \multicolumn{3}{l|}{} \\
\hline Active SLE\& Inactive SLE & Active SLE\& Control & Inactive SLE\& Control \\
\hline 0.001 & 0.001 & $\mathbf{0 . 0 0 1}$ \\
\hline
\end{tabular}

$* *$ p.value $\leq \mathbf{0 . 0 0 1}$ is highly significant. $\quad *$ p.value $\leq 0.05$ is significant.

.Table (2): Correlation between serum neopterin levels and some laboratory parameters among the active and the inactive SLE patients.

\begin{tabular}{|c|c|c|c|c|}
\hline & \multicolumn{4}{|c|}{ Serum neopterin } \\
\hline & \multicolumn{2}{|c|}{ Active SLE } & \multicolumn{2}{|c|}{ Inactive SLE } \\
\hline & $\mathbf{R}$ & p. value & $\mathbf{R}$ & p. value \\
\hline C3 & -0.585 & 0.001 & -0.199 & 0.299 \\
\hline $\mathrm{C4}$ & -0.259 & 0.166 & -0.319 & 0.091 \\
\hline Anti DNA & $\mathbf{0 . 0 3 7}$ & 0.829 & 0.024 & 0.900 \\
\hline ESR & 0.616 & 0.001 & -0.062 & 0.750 \\
\hline SLEDAI score & 0.830 & 0.001 & -0.166 & 0.389 \\
\hline HB & -0.284 & 0.128 & -0.164 & 0.415 \\
\hline PLT & -0.268 & 0.152 & -0.118 & 0.541 \\
\hline 24 PTN & 0.445 & 0.014 & 0.024 & 0.904 \\
\hline WBC & -0.293 & 0.116 & -0.359 & 0.056 \\
\hline
\end{tabular}

$* *$ p. value $\leq 0.001$ is highly significant.

*p. value $\leq \mathbf{0 . 0 5}$ is significant.

Figure (1): The mean values of serum neopterin level in the three groups

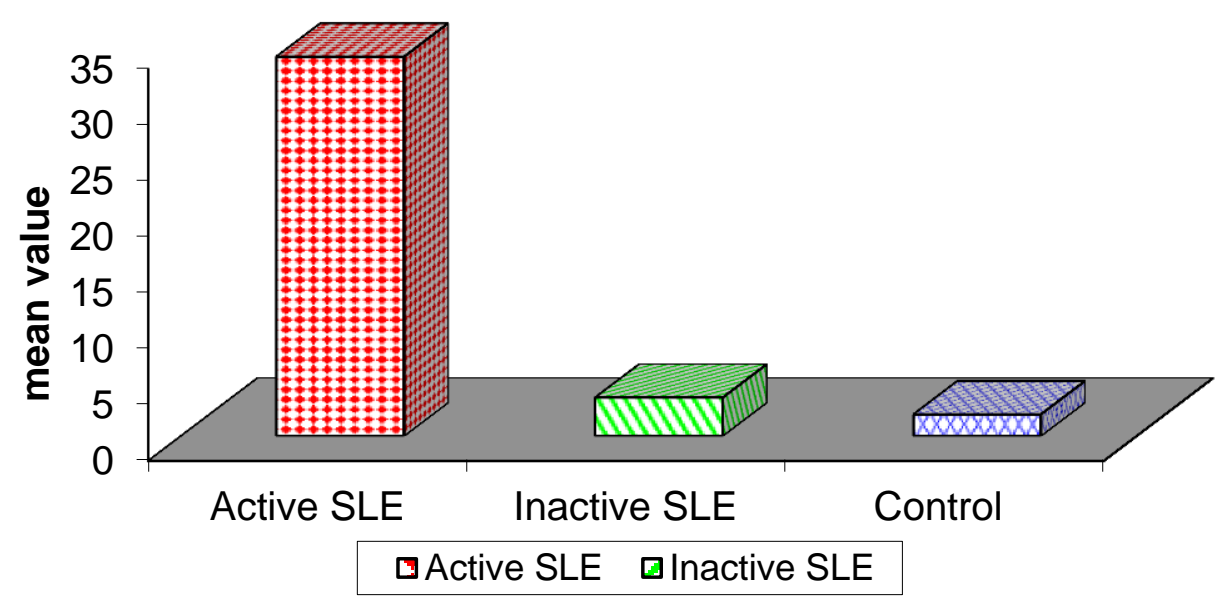

Show elevation of the serum neopterin in the active group in comparison of the inactive group and control and this elevation is highly significant 
Farag Khalil et al.

Table (3): Distribution of laboratory parameters among SLE patients and control group.

\begin{tabular}{|c|c|c|c|c|c|c|c|c|}
\hline & & Active SLE & $\begin{array}{l}\text { Inactive } \\
\text { SLE }\end{array}$ & Control & $\begin{array}{l}\text { p. } \\
\text { value }\end{array}$ & $\begin{array}{l}\text { Active } \\
\text { SLE\& } \\
\text { Inactiv } \\
\text { e SLE }\end{array}$ & $\begin{array}{l}\text { Active } \\
\text { SLE\& } \\
\text { Contro } \\
\text { l }\end{array}$ & $\begin{array}{l}\text { Inactiv } \\
\text { e } \\
\text { SLE\& } \\
\text { Contro } \\
\text { l }\end{array}$ \\
\hline \multicolumn{2}{|l|}{$\mathrm{C3}$} & $41.8 \pm 14.9$ & $48.3 \pm 13.4$ & $81.9 \pm 23.2$ & 0.009 & 0.024 & 0.001 & 0.001 \\
\hline \multicolumn{2}{|c|}{ ESR } & $77 \pm 30.7$ & $49.6 \pm 18.1$ & $18.6 \pm 4.64$ & 0.001 & 0.001 & 0.001 & 0.002 \\
\hline \multicolumn{2}{|l|}{$\mathrm{C} 4$} & $34.2 \pm 10.4$ & $57.8 \pm 14.3$ & $70.7 \pm 22.6$ & 0.002 & 0.009 & 0.001 & 0.007 \\
\hline \multirow{3}{*}{$\begin{array}{l}\text { Anti } \\
\text { DN } \\
\text { A }\end{array}$} & No & $6(20 \%)$ & $22(73.3 \%)$ & $20(100 \%)$ & \multirow{3}{*}{0.004} & & & \\
\hline & Yes & $24(80 \%)$ & $8(26.7 \%)$ & - & & & & \\
\hline & $\begin{array}{l}\text { Tota } \\
\text { l }\end{array}$ & $30(100 \%)$ & $30(100 \%)$ & $20(100 \%)$ & & & & \\
\hline
\end{tabular}

$* *$ p.value $\leq \mathbf{0 . 0 0 1}$ is highly significant.

*p. value $\leq \mathbf{0 . 0 5}$ is significant.

Table (4): Correlation between C3, C4 and Anti ds DNA among SLE patients.

\begin{tabular}{|l|l|l|l|l|}
\hline \multicolumn{4}{|l|}{} & \multicolumn{2}{l|}{} \\
\hline & Anti DNA & Inactive SLE & p. value \\
\cline { 2 - 5 } & retive SLE & p. value & r. & $\mathbf{0 . 0 9 5}$ \\
\hline C3 & -0.352 & 0.042 & $\mathbf{- 0 . 2 5 8}$ & $\mathbf{0 . 0 4 1}$ \\
\hline C4 & $-\mathbf{0 . 2 9 6}$ & $\mathbf{0 . 0 3 0}$ & $\mathbf{- 0 . 3 3 4}$ & \\
\hline
\end{tabular}

$* *$ p.value $\leq \mathbf{0 . 0 0 1}$ is highly significant.

*p.value $\leq \mathbf{0 . 0 5}$ is significant.

Table (5): The correlation between Anti ds DNA and C3 and C4 in whole patients.

\begin{tabular}{|l|l|l|}
\hline \multirow{2}{*}{} & Anti- ds DNA & p. value \\
\cline { 2 - 3 } & r. & $\mathbf{0 . 0 4 2}$ \\
\hline C3 & -0.362 & 0.049 \\
\hline C4 & -0.296 & \\
\hline
\end{tabular}

**p.value $\leq \mathbf{0 . 0 0 1}$ is highly significant.

*p.value $\leq \mathbf{0 . 0 5}$ is significant.

Table (6): Proteinuria level among SLE patients and control group.

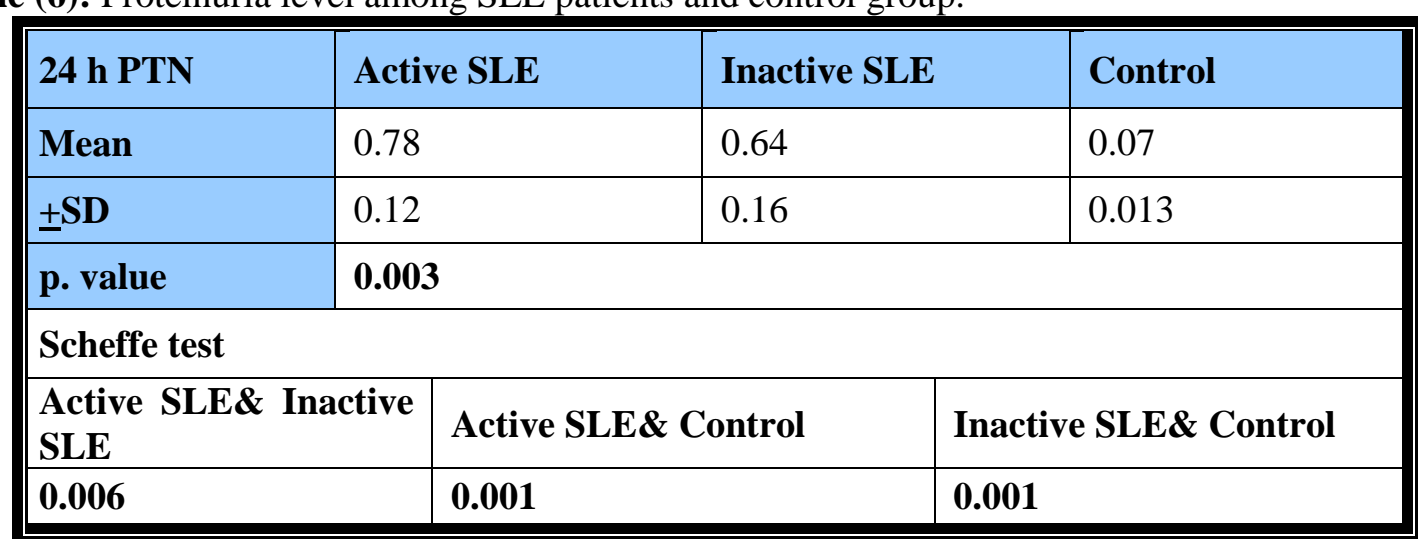

**p.value $\leq \mathbf{0 . 0 0 1}$ is highly significant.

*p.value $\leq \mathbf{0 . 0 5}$ is significant. 
Figure (2): 24 hour urine protein level in the three groups

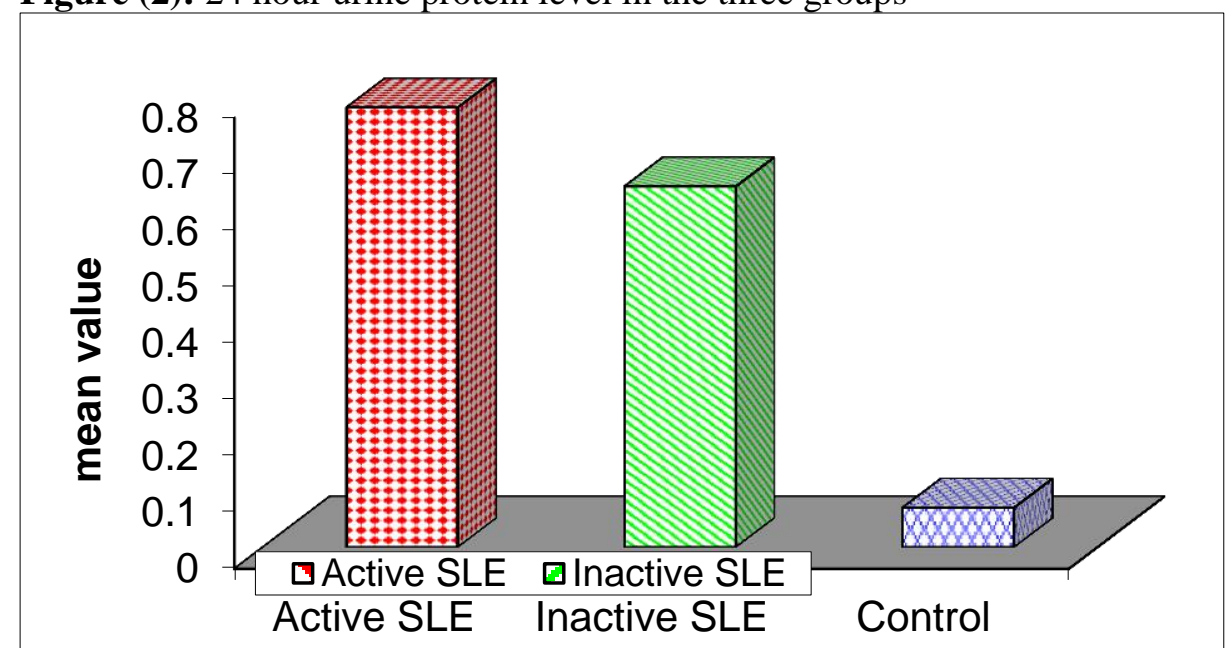

Show elevation of 24 hour urine protein in the active group in comparison to the inactive and control groups and this elevation is highly significant $p$. value $\leq 0.001$.

Figure (3): The correlation between serum neopterin and C3 in the active SLE.

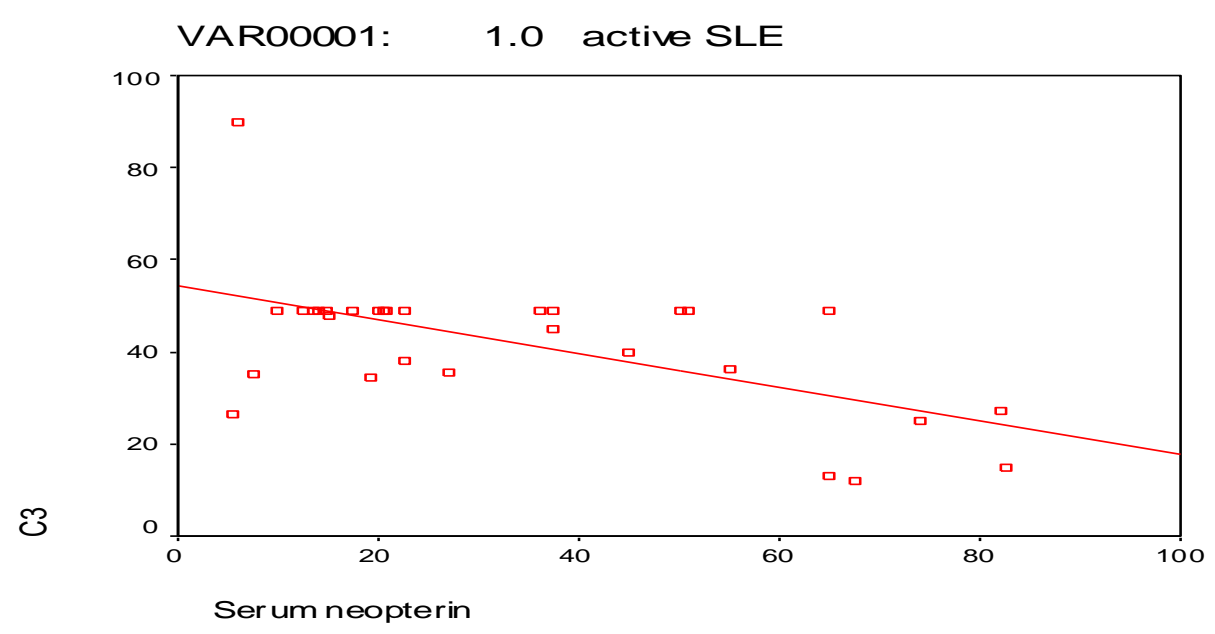

Figure (4): The correlation between serum neopterin and C3 in the inactive SLE.

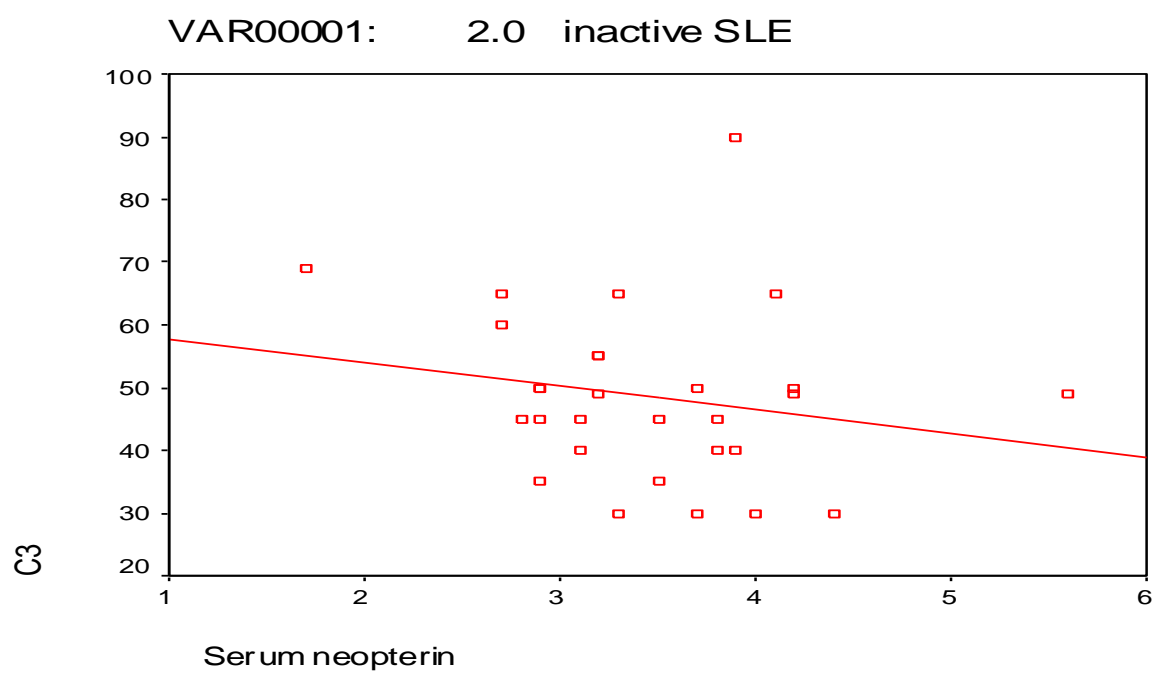


Figure (5): The correlation between serum neopterin and C4 in the active SLE

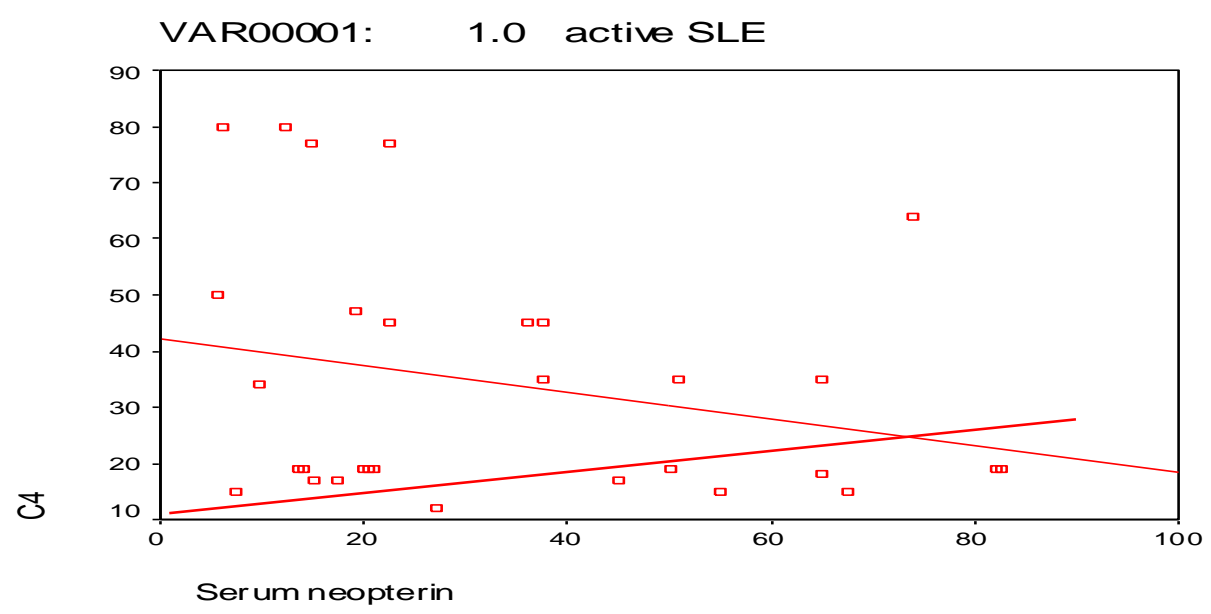

Figure (6): The correlation between serum neopterin and C4 in the inactive SLE.

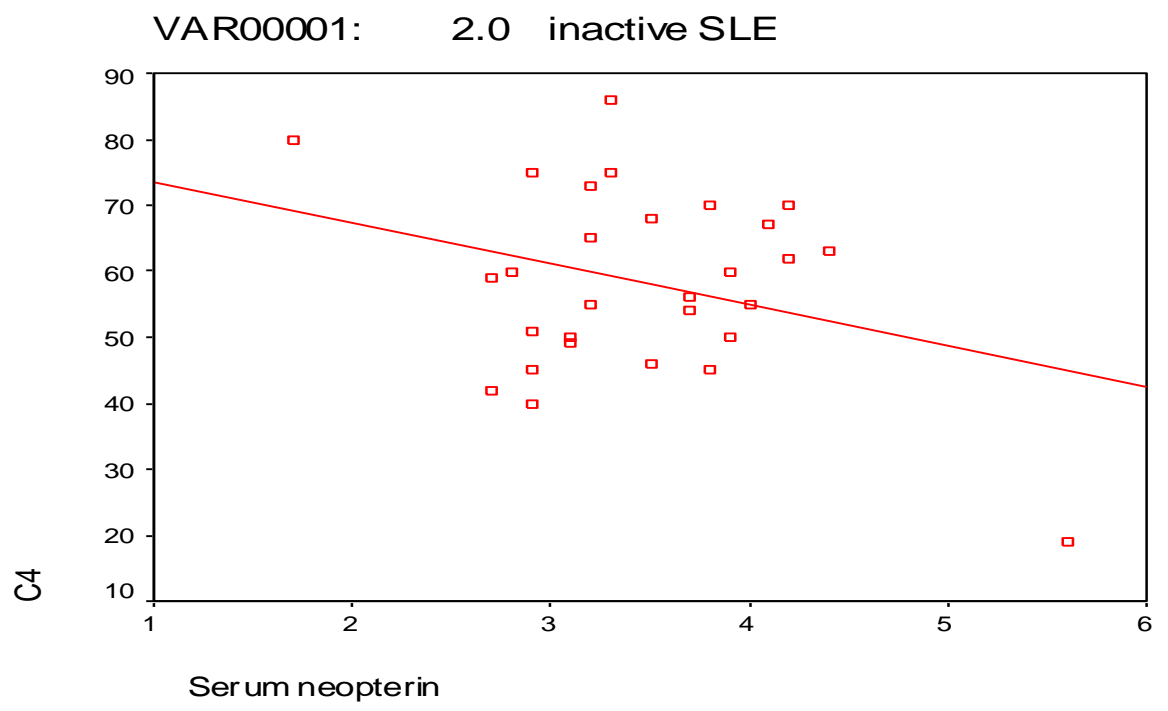

Figure (7): The correlation between serum neopterin and Anti ds DNA in the active SLE.

VAR00001: 1.0 active SLE

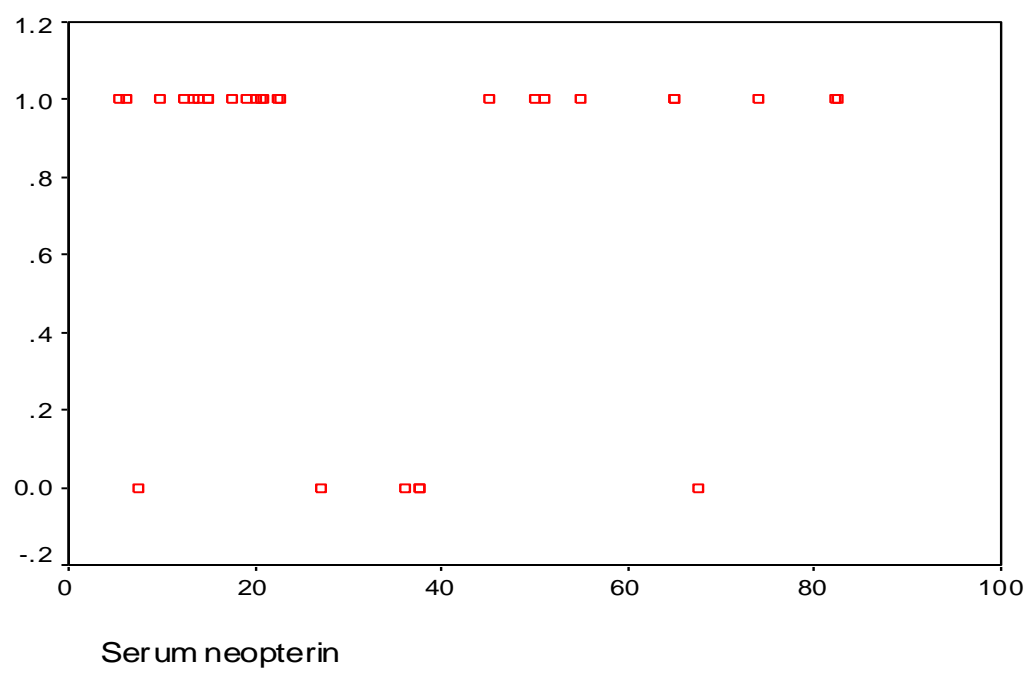


Correlation of Serum Neopterin level with Complement C3, C4 in assessment...

Figure (8): The correlation between serum neopterin and Anti ds DNA in the inactive SLE.

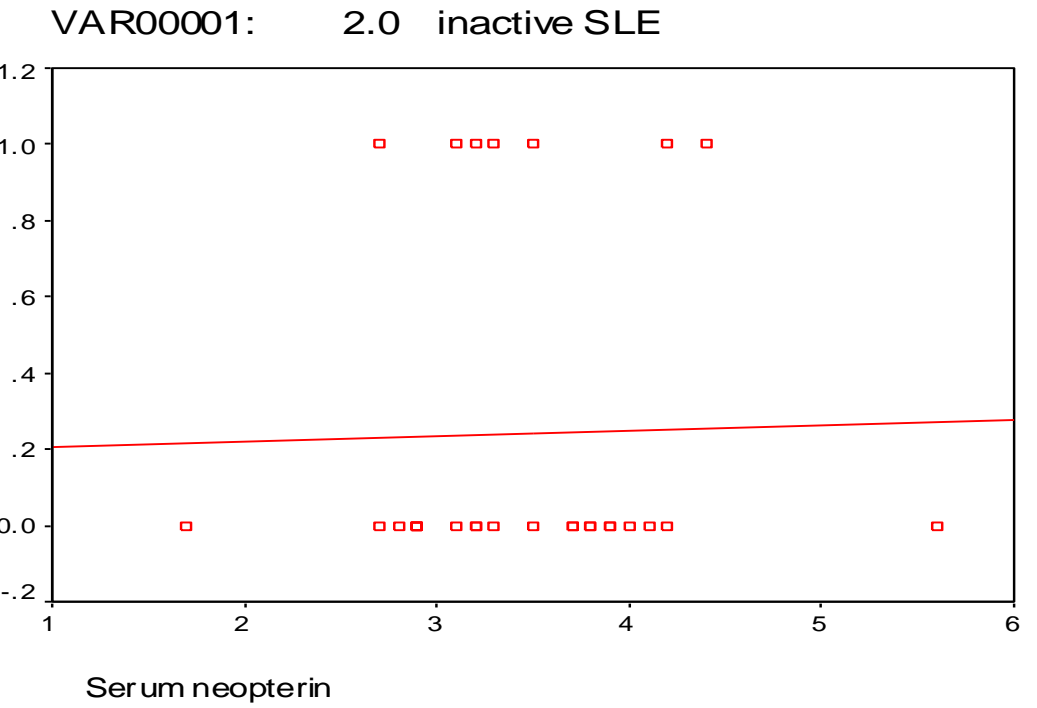

Figure (9): The correlation between serum neopterin and SLEDAI in the active SLE.

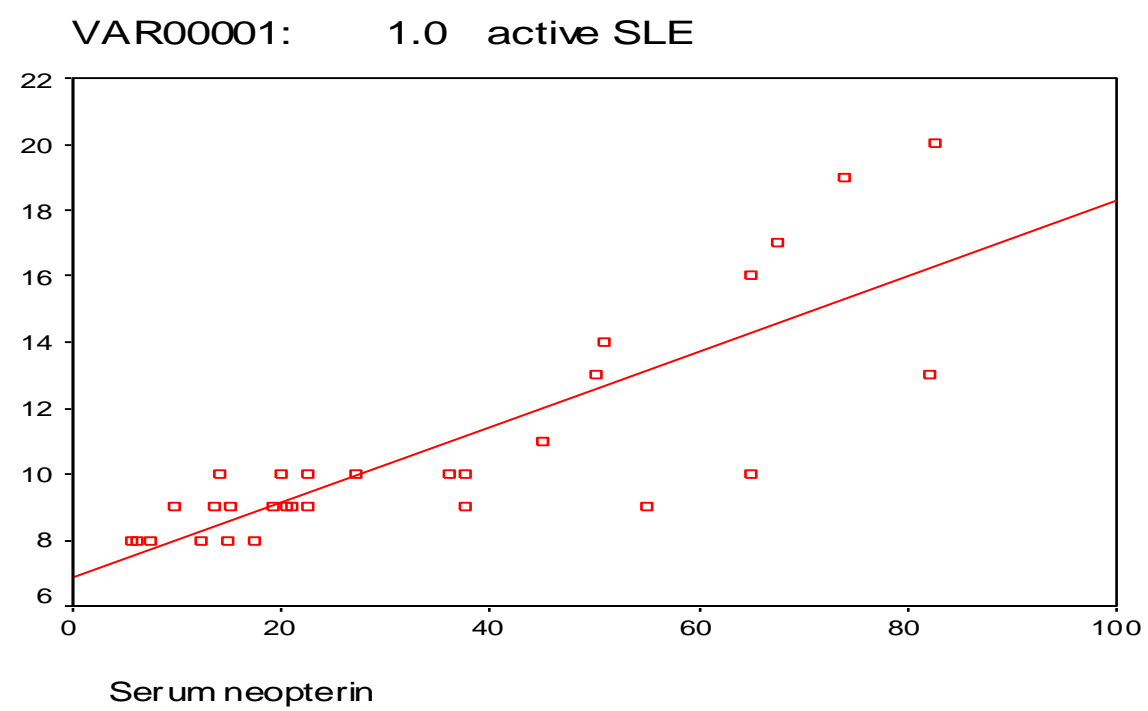

Figure (10): The correlation between serum neopterin and SLEDAI in the inactive SLE.

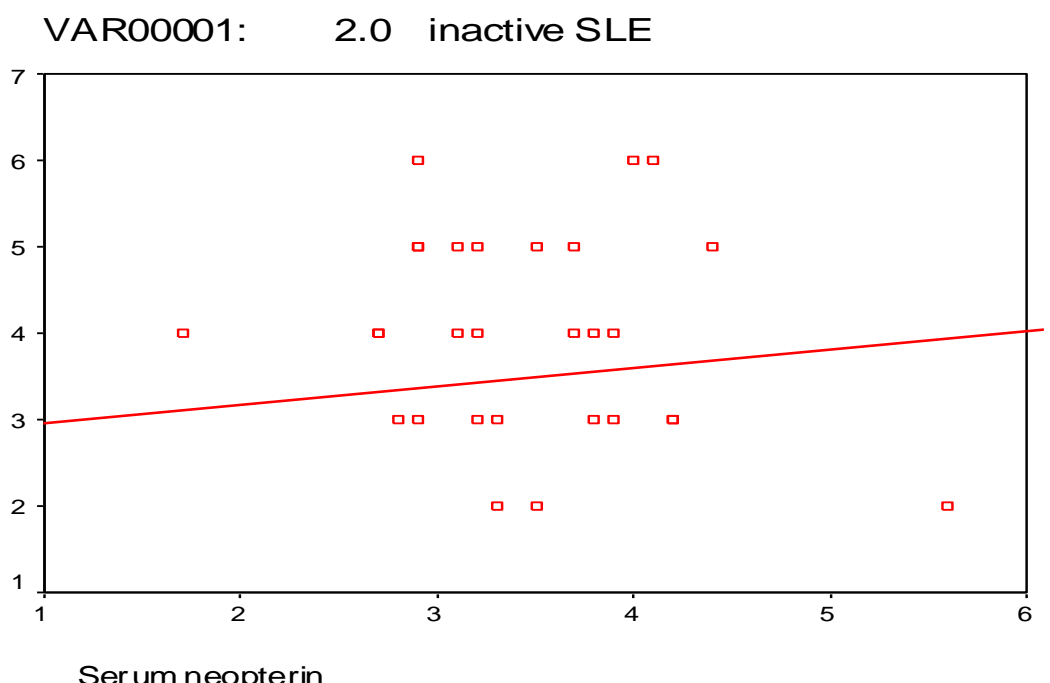


Figure (11): The correlation between serum neopterin and $24 \mathrm{~h}$ urine protein in the active SLE.

VAR00001:

1.0 active SLE

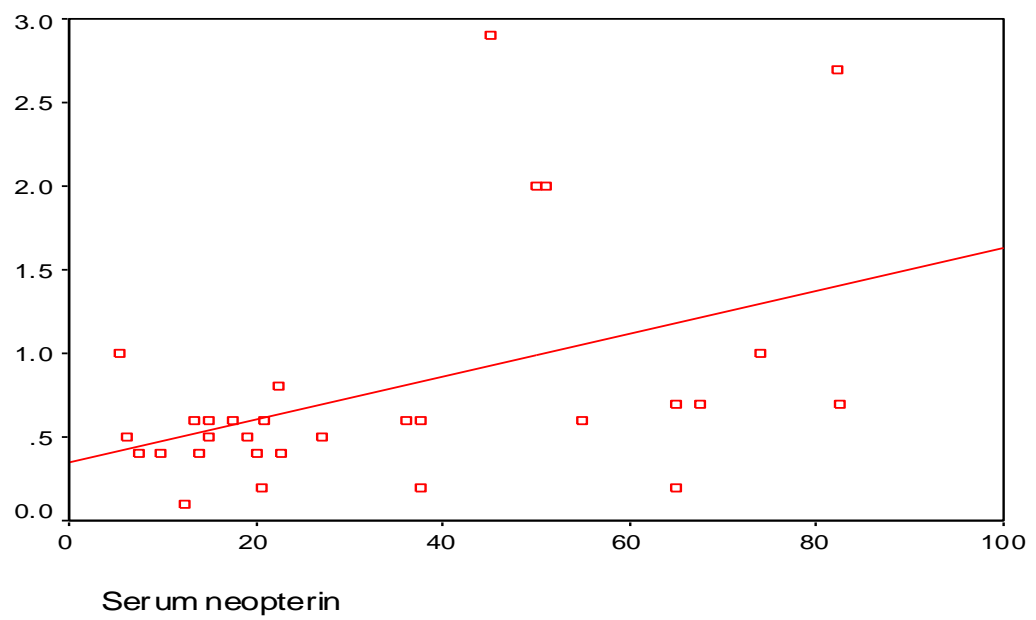

Figure (12): The correlation between serum neopterin and 24h urine protein in the inactive SLE.

VAR00001: 2.0 inactive SLE

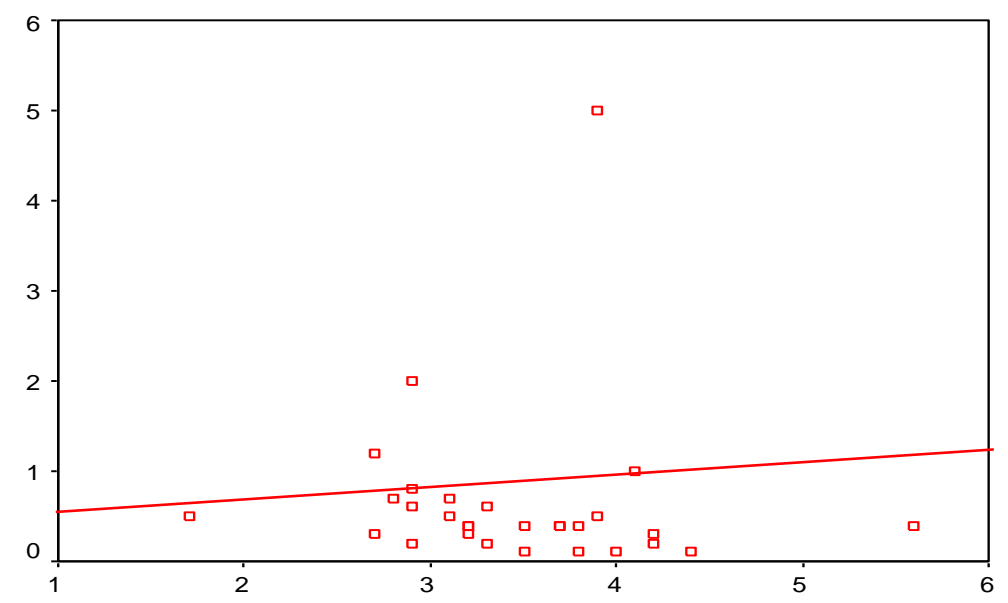

Serum neopterin

\section{Discussion}

In this study evaluation of serum neopterin and comparison between the active and the inactive systemic lupus erythematosus patients and healthy control group revealed that serum neopterin was significantly higher in the active group than in the inactive group and also significantly higher in the group of patients with systemic lupus erythematosus in comparison to control groups. As mean values of serum neopterin for the active and inactive groups was $33.9 \mathrm{ng} / \mathrm{ml}$ and $3.45 \mathrm{ng} / \mathrm{ml}$ respectively where they were highly significant than the mean value of the control group $(1.95 \mathrm{ng} / \mathrm{ml})$ $(\mathrm{P}<0.001)$. Also the differences between the three groups was highly significant $(\mathrm{P}<0.001)$. And this agree with study of ${ }^{(7)}$ that reported that serum neopterin and STNFRII were the only measured parameters that show significant increase in patients with lupus nephritis as well as neuropsychiatric lupus.

Also our study agree with wais et al., ${ }^{(8)}$ study that showed significant difference between SLE patients and healthy controls, also between the active and the inactive patients with SLE patients and also concoluded that patients with clinical remission showed ongoing systemic immuneinflammatory activity measured with TNF, STNFRII and serum neopterin.

One of the main findings of the current study was that the increased serum neopterin level showed higher significant than other SLE 
markers $(80 \%)$. These findings confirmed that there was a continuous low grade activation of the cellular immune system in patients with SLE even if the disease is inactive and without being associated with clinical symptoms. Which was in agree with the study ${ }^{(9)}$.

The increased level of serum neopterin was explained by the assumption that it might be an attempt of the patients' macrophage system to remove the apoptotic cell excess ${ }^{(5)}$.

So they concluded that serum neopterin may be regarded as an index of SLE disease activity. This agree with findings in the present study, where serum neopterin level showed a highly significant positive correlation with each of ESR, C3dg, and anti-dsDNA, and a significant negative correlation with both levels of $\mathrm{C} 3$ and $\mathrm{C} 4{ }^{(5)}$.

The SLAM score (systemic lupus activity measures) also correlated with serum neopterin level. This study supported serum neopterin level also correlate with overall lupus disease activity they may be regarded as an index of SLE disease activity.

Determination of serum anti-ds DNA titter and complement levels $(\mathrm{C} 3, \mathrm{C} 4)$ are the most common and useful tests for assessing the disease activity and predicting flares in SLE (10).

The current work demonstrated a significant increase in anti-ds-DNA antibodies level in the active SLE patients in comparison to patients in remission. p.value $\leq 0.001$ is highly significant. On correlation of the anti- dsDNA and C3, C4 the p.value was $\leq 0.05$ which is negatively significant in patients with active SLE. In patients with inactive SLE there was negative insignificant correlation between C3 and anti-ds DNA, however the correlation between $\mathrm{C} 4$ and Anti ds DNA was negative and significant.

Combination of anti-dsDNA, serum complement $\mathrm{C} 3$ and $\mathrm{C} 4$, ESR and CRP, supported by relevant tissue histology, probably provides the most useful information on disease activity particularly in patients with lupus nephritis. However results of any laboratory test should always be interpreted with reference to the clinical presentation ${ }^{(11)}$.

Both these tests have their limitation, in that elevated anti-dsDNA antibodies and hypocomplementemia do not occur in all patients and their correlation with disease activity is not absolute. Patients can have persistently elevated anti-dsDNA antibodies titer without evidence of clinical disease for several months ${ }^{(\mathbf{1 2})}$.

Predictive value of various serological tests in SLE depends on many factors such as criteria used for define and measure disease activity, effect of drug therapy, immunological methods used to measure serologic parameters and the type of study, whether cross sectional or long term prospective study. Hence comparison of the results of various studies is difficult ${ }^{(\mathbf{1 0})}$.

The present study show that there was a significant difference between the active and the inactive SLE patients as regards presence of anti-ds DNA, which agree with AbdElsamad, $200{ }^{(13)}$.

However some authors observed that raised anti-dsDNA titer is of no significance and may be found raised in quiescent diseases ${ }^{(\mathbf{1 4})}$.

In the present study it was found that is a significant difference between the active group and in active group with SLE as regard complement $(\mathrm{C} 3)$ level $(\mathrm{p}<0.05)$. This agrees with one study (15), who found highly significant difference between active SLE patients with reduced $\mathrm{C} 3$ level comparing with inactive SLE patients $(\mathrm{p}<0.001)$ and they concoluded that $\mathrm{C} 3$ provides the best assessment of disease activity in patients with SLE.

However some authors observed that C3 level was low in active stage of SLE especially during clinical exacerbation but its concentration was often normal in mild to moderate active stage ${ }^{(\mathbf{1 6})}$.

The present study showed that significant difference was found in complement (C4) in patients with SLE on comparing active and inactive groups. Level of $\mathrm{C} 4$ concentration was lower in the active groups than of inactive groups of SLE. This agrees with the study of Abd-Elsamad, $2000^{(\mathbf{1 3})}$.

So several studies showed that the level of (C3, C4) is low in active SLE patients comparing with that of inactive patients ${ }^{(17)}$.

While some studies said that the level of complement (C3, C4) shows no significant difference between active and inactive SLE patients, and does not reflect the activity of the disease $^{(\mathbf{1 8})}$.

Inspite of the many years of study of the disease, the pathology or disease process in systemic lupus erythematosus remains unclear. Various laboratory tests were used for 
detection of the activity of the disease as ESR, plasma complements concentrations, and formation of autoantibodies. Particular attention was focused on neopterin as an important indicator for assessing SLE activity. The present study showed significant decrease in $\mathrm{RBC}, \mathrm{WBC}$ and platelet counts in patients with active SLE compared to patients in remission, as well as, to the healthy controls. Decreased RBC count could be explained by impaired renal function with decreased erythropoietin formation, also due to poor general condition, cachexia and anorexia, in addition to bone marrow suppression by aggressive cytotoxic therapy ${ }^{(\mathbf{1 6})}$.

Leucopenia in SLE patients occurs as part of drug toxicity-induced medullary hypoplasia. Also, it may be due to disease activity, bone marrow failure, peripheral destruction and sepsis. The most common mechanism of thrombocytopenia in SLE patients is believed to be increased platelet clearance mediated by anti-platelet auto-antibodies ${ }^{(19)}$. ESR was significantly higher comparing active SLE patients to patients in remission and healthy controls, and was significantly higher comparing patients in remission to controls. Plasma levels of $\mathrm{C} 3$ and $\mathrm{C} 4$ were significantly decreased comparing SLE patients to healthy normal subjects, also, significant decrease in their levels were found comparing active SLE patients with patients in remission. This could be attributed to reduction of their synthesis and, also, their consumption in immune complex formation. These results indicated that complement dysfunction may be an important factor in the pathophysiology of SLE.

Regarding the level of ESR, our study revealed a significant difference between active and inactive SLE patients. The level of ESR was higher in active group than in inactive group and this agrees with some studies ${ }^{(20)}$.

While some authors found no relation between ESR level and disease activity in SLE ${ }^{(\mathbf{2 1})}$.

In our study we found that presence of proteinuria showed significant difference in disease activity in SLE patients and this study agree with ${ }^{(22)}$ who found that patient with activity of disease show high concentration of proteinuria especially those who have renal involvement.

However some authors found that there is no significant difference in proteinuria and disease activity in patients with systemic lupus erythematosus.

Serum neopterin showed a positive correlation with ESR, anti-ds DNA antibodies and proteinuria level in systemic lupus erythematosus patients and a negative correlation with complement level $(\mathrm{C} 3, \mathrm{C} 4)$ in patients with systemic lupus erythematosus, which agrees with the study of El Ghandour et al., $2007^{(11)}$.

The physiological role and disordered production of cytokines needs still further investigations in order to get a better understanding of the nature of dysfunction immune system in SLE patients ${ }^{(23)}$.

We suggested that serum neopterin level may be a helpful marker for predicting disease activity and prognosis in patients with SLE. Its level may predict the risk of organ damage at an early stage. This should be confirmed by a prospective long term study in a larger group of patient and this agrees with the findings of Bohuslav Melichar et al., ${ }^{(24)}$ which said that neopterin is a biomarker of immune activation increased in different disorders associated with immune activation.

In patient with SLE, serum neopterin may be used to evaluate the SLE disease activity and efficacy of treatment, so we recommended its use in follow up of such patients.

Conclusion: The present results showed that the increased serum neopterin level found in patients with SLE disease was correlated with clinical and laboratory immunoinflammatory parameters denoting activity. So the estimation of serum neopterin levels seems beneficial in the assessment of disease activity and progression of the disease as well as the assessment of the efficacy of various treatment regimens used.

\section{References}

1. Hochberg MC, Silman AJ. Smolen JS (2011): Rheumatology. 5th ed. Philadelphia, PA; Elservier; Chap. 132.

2. Voet D, Voet JG(2004): Biochemistery.3rd ed. John Wiley and Sons, PP 39223-5.

3. Sucher R, Schroecksnadel K, Weiss G, Marhreiter R, Fuchs D, Brandacher G(2010): Neopterin a prognostic marker in human malignancies. Cancer let., 287:13-22. 
4. Klos A, Wende E, Wareham KJ,

PN(2013):International Union of Pharmacology. LXXXVII. Complement peptide C5a, C4a, and $\mathrm{C} 3 \mathrm{a}$ receptors. Pharmacol. Rev., 65 (1): 500-43.

5. Col K Narayanan, Col V Marwaha, Col K Shanmuganandan, Gp Capt $S$ Shankar (2010) : Correlation between Systemic Lupus Erythematosus Disease Activity Index, C3, C4 and Anti-dsDNA Antibodies: MJAFI ., 66 : 102107.

6. Hochberg MC (1997): Revised criteria of the American College of Rheumatology for the classification of SLE. Modified from Hochberg, Arthritis Rheum., 40: 1725-34.

7. Mahmoud RA, El-Gendi HI, and Ahmed HH (2005): Serum neopterin, tumor necrosis factor receptor II (p75) levels and disease activity in Egyptian female patients with systemic lupus erythematosus.Clin Biochem.., 38(2):134-41.

8. Wais T, Fierz W, Stoll T, Villiger A (2003): Subclinical disease activity in systemic lupus erythematosus immunoinflammatory markers do not normalize in clinical remission. $J$. Rheumatol., 30: 2133- 9.

9. Jin O, Sun LY, Zhou KX, Zhang XS, Feng XB, Mok MY and Lau CS (2005): Lymphocyte apoptosis and macrophage function: correlation with disease activity in systemic lupus erythematosus: Clin Rheumatol., 24 (2): 107- 10.

10. Wirleitner B, Neurauter G, Schrocksnadel $\mathrm{K}$ et al. (2003): Interferongamma-induced conversion of tryptophan: immunologic and neuropsychiatric aspects. Curr Med Chem.,10(16):1581 -91 .

11. El Ghandour N, Abd El Aziz H, Marzouk S, AndMarwa Ahmad (2007): Serum Neopterin level in Systemic Lupus Erythematosus: Relation to Disease Activity,
Organ Affection and Different Therapy Regimens, Bull Egypt. Soc. Physiol. Sci., 27 (2) 233247.

12. Gordon K. W. Lam, MD; Michelle Petri, MD, MPH. (2005): Assessment of Systemic Lupus Erythematosus, Clin Exp Rheumatol .23 (39): S 120S132.

13. Abd-Elsamad E, Mazen $M$, Nagwa $A$ and Yousry $M$ (2000): Urine neopterin as a parameter of disease activity in patients with systemic lupus erythematosus: comparison with antibodies to double stranded DNA and serum complement (C3, C4): thesis MD degree, Zagazig University .

14. HO A, Barr SG, Magder LS, Petri M (2003): A decrease in complement is associated with increased renal and hematologic activity in patients with systemic lupus erythematosus. Arthritis Rheum., 44: 2350-7.

15. Wang XY, Tang XQ, Huang YJ, Chen WY and Yu XQ (2012): Frequency of established cardiovascular disease and its risk factors in Chinese patients with SLE. Clin Rheumatol., 31(4): 669-75.

16. Rahman A, Hiepe F. (2002): Anti-DNA antibodies-overview of assays and clinical correlations. Lupus, 11(12): 770-773.

17. Ramos CM, Campomor MT, Chamorro A, Salvador G, (2004): Hypocomplementemia in systemic lupus erythematosus and phospholipid syndrome: prevalence and clinical significance in 667 patients. Lupus, 13: 777- 683.

18. Elwy MA, Galal ZA, Hasan HE (2010):Immuno- inflammatory markers and disease activity in systemic lupus erythematosus: something old, something new: East Mediterr Health J. , 16(8):893-900.

19. Kyttaris VC, Juang YT, Tsokos GC (2005): Immune cells and cytokines in systemic lupus erythematosus: an update. Current 
Opinion in Rheumatology, 17 (5):511512.

\begin{abstract}
20. Stojan G, Fang H, Magder L, Petri M (2013): Erythrocyte sedimentation rate is a predictor of renal and overall SLE disease activity. Lupus, 22 (8): 827- 34.
\end{abstract}

21. Zanana-Nacach A, Salas $M$, Sanchez M, Camargo Coronel A and Mintz Gregoria (1995): Measurement of clinical activity of systemic lupus erythematosus and laboratory abnormality : A 12 month prospective study submitted August 16, J. Rheumatol., 22: 45-9.
22. Michelle P, Lam G et al. (2007):Monitoring systemic lupus erythematosus in standard clinical care. Best Pract Res Clin Rheumatol., 21: 887-897.

23. Chi C (2010): Biomarkers for Lupus Nephritis: A Critical Appraisal: journal of Biomedical and Biotechnology

https://www.hindawi.com/journals/bm ri/2010/638413/

24. Bohuslav M, Martina S, Marie B et al. (2017): Neopterin as a biomarker of immune response in cancer patients: Ann Transl Med. , 5(13): 280. 